\title{
Environmental Sensitivity of Soybean Cultivar Response to Sclerotinia sclerotiorum
}

\author{
B. W. Pennypacker and M. L. Risius
}

Department of Agronomy, The Pennsylvania State University, University Park 16802.

Accepted for publication 26 April 1999.

ABSTRACT

\begin{abstract}
Pennypacker, B. W., and Risius, M. L. 1999. Environmental sensitivity of soybean cultivar response to Sclerotinia sclerotiorum. Phytopathology 89: 618-622.

The sporadic occurrence of Sclerotinia stem rot in soybeans often is attributed to the sensitivity of Sclerotinia sclerotiorum to environmental factors. Environmental sensitivity in soybean response to the pathogen also could contribute to the unpredictable nature of this disease. We used stability analysis to determine whether soybean cultivar response to $S$. sclerotiorum was sensitive to light and temperature. Five greenhouse experiments examined the response of seven cultivars to limited-term inoculation with S. sclerotiorum. The cultivars, selected at random from Pennsylvania variety trials, represented maturity groups grown in Pennsylvania and other states sharing that latitude. Photon flux density of photosynthetically active radiation (PAR) and temperature were recorded hourly and varied among experiments. Environmental sensitivity was detected in the response of five cultivars to $S$. sclerotiorum when individual cultivar disease ratings (assessed 6 days after inoculation) were regressed against the mean disease rating of each experiment. Stability analysis with tem-
\end{abstract}

perature during the 48-h inoculation period as the environmental index found that all cultivars responded similarly to the number of hours that temperatures were $<19^{\circ} \mathrm{C}, 19$ to $22^{\circ} \mathrm{C}$, or $>22^{\circ} \mathrm{C}$. In contrast, cultivars separated into PAR-sensitive and PAR-insensitive groups when the environmental index was moles of PAR at a photon flux density $\geq 475 \mu \mathrm{mol} \mathrm{m} \mathrm{m}^{-2} \mathrm{~s}^{-1}$ during the inoculation period. The photon flux density of PAR on a cloudy day in the field is $\leq 200 \mu \mathrm{mol} \mathrm{m} \mathrm{m}^{-2} \mathrm{~s}^{-1}$. The two cultivar groups were identical to those identified as environmentally sensitive and insensitive in the initial analysis. The PAR-sensitive cultivars had homogeneous negative regression coefficients different $(P=0.001)$ from zero. As the accumulated moles of PAR during the inoculation period increased, the disease ratings of the PAR-sensitive cultivars decreased; the disease ratings of the PAR-insensitive cultivars remained stable. The photon flux density of PAR during the 48-h inoculation period explained the environmental sensitivity of soybean cultivar response to $S$. sclerotiorum in these experiments.

Additional keywords: polygenic resistance, quantitative resistance, genotype $\times$ environment interactions.
Sclerotinia stem rot (white mold) caused by Sclerotinia sclerotiorum (Lib.) de Bary was a minor problem on soybean (Glycine max (L.) Merr.) in the United States prior to 1994. The disease occurred primarily along the northern boundary of the midwestern soybean production region and caused severe but localized losses when environmental conditions were conducive to disease development (13). In 1994, Sclerotinia stem rot appeared in Illinois, Indiana, and Iowa (2); the major U.S. soybean-producing states (28). Agronomic practices designed to increase soybean yield (narrow row spacing, high plant densities, and early planting dates), rotation with susceptible crops, and seed transmission of $S$. sclerotiorum may be involved in the recent increase in the incidence of Sclerotinia stem rot $(13,15,22$, 30). S. sclerotiorum reduces yield by $0.23 \mathrm{Mg} / \mathrm{ha}$ for every $10 \%$ increase in disease incidence (6). The increase in Sclerotinia stem rot in the major U.S. soybean production region is of concern because of the scarcity both of resistant cultivars in the maturity groups appropriate for the Midwest (13) and of fungicides labeled for use against Sclerotinia stem rot in soybean $(4,5,14,23)$.

Cultural practices including wide row spacing, cultivation, and irrigation timing can reduce losses caused by S. sclerotiorum $(15$, 29). However, when available, host resistance is the most reliable control method. S. sclerotiorum infects soybean plants through senescing flower petals. Soybean cultivars reported to have a degree of resistance often simply escape infection by flowering before the pathogen sporulates (13). Others have an upright, open architecture that reduces lodging and allows air movement through the

Corresponding author: B. W. Pennypacker; E-mail address: p1q@psu.edu

Publication no. P-1999-0610-01R

(C) 1999 The American Phytopathological Society canopy. Increased air movement in the canopy lowers the humidity, which inhibits pathogen growth (4).

Physiological resistance in soybean to $S$. sclerotiorum was observed in greenhouse and growth chamber experiments $(3,7,24)$ but is difficult to demonstrate in the field due to the propensity for plants to escape infection. Physiological resistance in soybean is characterized by restricted, reddish-brown lesions at the inoculation site $(7,13,24)$. Physiological resistance to $S$. sclerotiorum in dry bean (Phaseolus vulgaris) (21) is inherited polygenically (11); preliminary evidence (B. W. Pennypacker, unpublished data) indicates that it may be similarly inherited in soybean.

Plant breeders consider yield stability across environments an important breeding goal and assume that disease resistance facilitates yield stabilization (16). However, disease resistance that is sensitive to environmental factors such as light or temperature may confound plant breeders' efforts to stabilize yield. Polygenic resistance in alfalfa to Verticillium albo-atrum is sensitive to light levels (25), and soybeans etiolated by insufficient light appear to be more susceptible to $S$. sclerotiorum than are nonetiolated plants (7). Whether disease resistance contributes to yield stability may depend on the genetic basis of the resistance.

Sclerotinia stem rot resistance is difficult to identify consistently in the field due to disease escape $(5,23)$. Greenhouse and laboratory screening avoid that problem, but there is little correlation between field results and those from the greenhouse or laboratory $(4,6,14)$. S. sclerotiorum is sensitive to temperature and moisture $(1,13)$, but little is known about the environmental sensitivity of the host-pathogen interaction. Polygenic resistance is sensitive to light (25), and soybean appears to have polygenic resistance to $S$. sclerotiorum. We, therefore, hypothesized that the lack of correlation between greenhouse and field screening for Sclerotinia stem 
rot resistance might be due to environmental sensitivity in soybean response to the pathogen. The objective of our research was to use stability analysis to examine the light and temperature sensitivity of soybean response to $S$. sclerotiorum.

\section{MATERIALS AND METHODS}

Plant material. Seven soybean cultivars (Table 1) from maturity groups 2 and 3 were used in five experiments in 1996 and 1997. The cultivars, selected at random from Pennsylvania variety trials, represented maturity groups grown in Pennsylvania and other states with a similar latitude. Soybeans were grown from seed in 10-cm-diameter plastic pots filled with Redi-Earth Peat-Lite Mix (E.C. Geiger, Inc., Harleysville, PA) and then thinned to one plant per pot. Plants were fertilized with $14 \%$ N-P-K slow-release fertilizer (Osmocote; E.C. Geiger, Inc.) in lieu of inoculation with Rhizobium japonicum to assure a uniform level of nitrogen fertility among experimental units. Plants were inoculated with S. sclerotiorum when they had two to three trifoliolate leaves, which corresponded to soybean vegetative growth stages V2 and V3.

Inoculum production. Inoculum production took place in the laboratory at $\sim 21^{\circ} \mathrm{C}$ with a 12 -h photoperiod. The isolate of $S$. sclerotiorum was obtained from L. Rhodes, Ohio State University, and was maintained as sclerotia. Inoculum was prepared by placing a sclerotium in the center of a 9-cm-diameter petri plate of potato dextrose agar. The sclerotium germinated myceliogenically, and the mycelium was used for inoculum production after $\sim 80$ to $90 \%$ of the agar surface was colonized.

Inoculum production was similar to that of Hunter et al. (18), except that carrot was chosen as the exogenous nutrient source because its color facilitated inoculum monitoring and removal. Carrot roots $\sim 10 \mathrm{~mm}$ in diameter were sliced into 3-mm-thick disks that were then subdivided into six triangular pieces. The carrot pieces were autoclaved for $15 \mathrm{~min}$ at $121^{\circ} \mathrm{C}$ and then aseptically placed around the growing edge of the $S$. sclerotiorum culture and incubated for 15 to $18 \mathrm{~h}$ at $21^{\circ} \mathrm{C}$. Colonization of the carrot pieces was confirmed by microscopic examination before they were used as inoculum.

Growing conditions, inoculation method, and disease assessment. The experiments were conducted during the winter months of October to March. Plants were placed on greenhouse benches equipped with a solenoid-controlled mist system that was regulated with a timer. The mist nozzles produced a fine, foglike mist at a frequency that kept the foliage wet for the duration of each experiment. Natural light was supplemented with 400-W high-intensitydischarge lamps. The photoperiod was $15 \mathrm{~h}$ during all experiments.

The inoculation method was a modification of the limited-term inoculation method of Hunter et al. (18) and Cline and Jacobsen (7). Plants were inoculated by placing one piece of carrot root inoculum in the axil of the oldest trifoliolate leaf and then pressing the inoculum to the main stem. The inoculum was removed after $48 \mathrm{~h}$. Plants were rated for disease symptoms 6 days after inoculation using a 1 to 6 scale $(1=$ no symptoms, $2=$ a restricted lesion $[<1 \mathrm{~cm}]$ on the petiole or main stem, $3=$ petiole collapse and a restricted lesion $[<1 \mathrm{~cm}]$ on the main stem, $4=$ large lesion on the main stem $[>1 \mathrm{~cm}], 5=$ apical portion of the stem collapsed, and $6=$ plant dead).

TABLE 1. Identification code, source, and maturity group of soybean cultivars evaluated for response to Sclerotinia sclerotiorum

\begin{tabular}{lllc}
\hline Code & Source & Cultivar & Maturity group \\
\hline A & Public & Kenwood & 2 \\
B & Madison & GL2820 & 2 \\
C & Hoffman & 7253 & 2 \\
D & Asgrow & A3237 & 3 \\
E & Terra & Finalist & 3 \\
F & Asgrow & A3510 & 3 \\
G & Asgrow & A3304 & 3 \\
\hline
\end{tabular}

Environmental data. Photon flux density of photosynthetically active radiation (PAR) was monitored during each experiment with LICOR quantum sensors (LICOR, Lincoln, NE) located at canopy height. Temperature was measured with thermistors similarly positioned in the canopy. A Campbell $21 \times$ micrologger (Campbell Scientific, Inc., Logan, UT) was programmed to read the environmental sensors once a minute and record the hourly photon flux density of PAR and temperature averages. Environmental data were compiled using the PROC MEANS procedure in SAS (SAS Institute, Inc., Cary, NC).

Experimental design and statistical analysis. The five experiments were randomized complete blocks with six replications, and each cultivar was represented by two randomly arranged experimental units per block. The disease rating data were transformed with the square root transformation to control heteroscedasticity of error variances among experiments.

Stability analysis $(9,12,16)$ was used to examine cultivar response over experiments; the genotype $\times$ environment interaction. Stability analysis involves regression analysis with an environmental index as the independent variable, followed by tests for homogeneity of regression coefficients. S. sclerotiorum frequently macerated susceptible plants during the 48-h inoculation period. The rapid death of susceptible plants was evidence that physiological resistance must be expressed during the initial 48-h inoculation period to be effective. Consequently, we used environmental

TABLE 2. Correlation coefficients for moles of photosynthetically active radiation $\geq$ the specified photon flux densities accumulated during the 48-h inoculation period of five experiments correlated with disease ratings ${ }^{\mathrm{a}}$ (square root) of soybean cultivars in those experiments

\begin{tabular}{|c|c|c|c|c|}
\hline \multirow[b]{2}{*}{ Cultivar } & \multicolumn{4}{|c|}{ Photon flux density $\left(\mu \mathrm{mol} \mathrm{m} \mathrm{m}^{-2} \mathrm{~s}^{-1}\right)$} \\
\hline & $\geq 350$ & $\geq 425$ & $\geq 450$ & $\geq 475$ \\
\hline A & 0.79 & $0.86^{* \mathrm{~b}}$ & $0.87 *$ & $0.82^{*}$ \\
\hline B & -0.11 & 0.06 & -0.08 & -0.09 \\
\hline $\mathrm{C}$ & -0.56 & -0.72 & -0.72 & $-0.86^{*}$ \\
\hline $\mathrm{D}$ & -0.19 & -0.24 & -0.35 & -0.59 \\
\hline $\mathrm{E}$ & -0.41 & -0.44 & -0.61 & $-0.81 *$ \\
\hline $\mathrm{F}$ & -0.79 & -0.70 & $-0.97 *$ & $-0.96^{*}$ \\
\hline G & -0.39 & -0.57 & -0.59 & $-0.81^{*}$ \\
\hline
\end{tabular}

a The cultivars were inoculated with Sclerotinia sclerotiorum.

b $*=$ Correlation coefficient significant at $P \leq 0.10$.

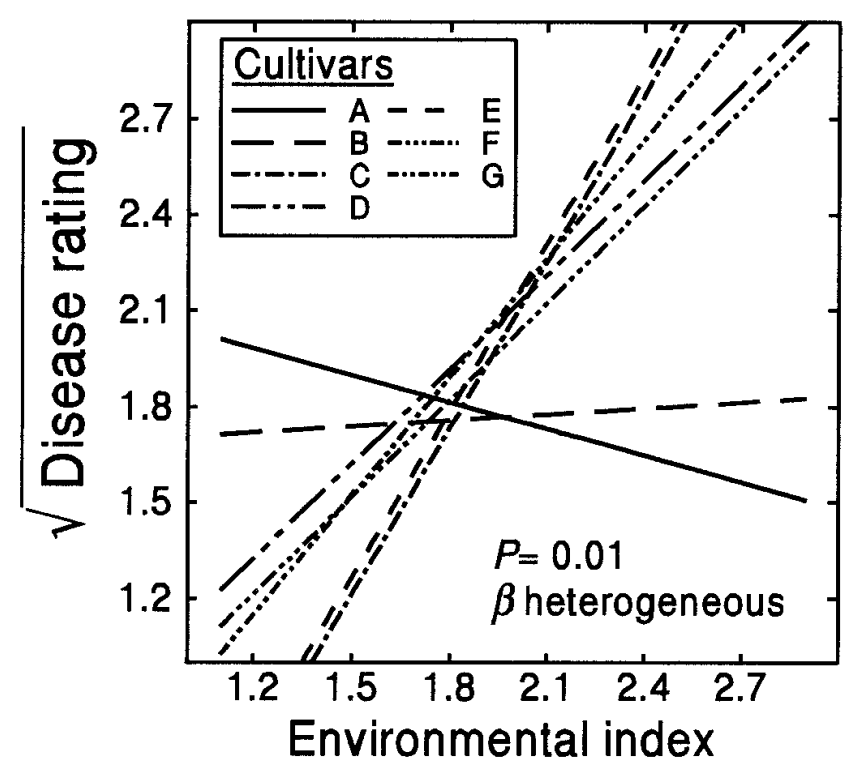

Fig. 1. Stability analysis of the response of seven soybean cultivars to Sclerotinia sclerotiorum in five experiments. The square root of the mean disease rating of each experiment was used as the environmental index. Note that the cultivar responses fall into two distinct groups. 
data from the 48-h inoculation period as the independent variable in stability analysis. The dependent variable for all stability analyses was the individual cultivar disease rating assessed 6 days after inoculation.

The environmental index for the initial stability analysis was the mean disease rating of each experiment. The cultivar disease rating averaged over replications for each experiment (12) was regressed against that environmental index using the General Linear Models PROC STEPWISE procedure in SAS. Regression coefficients $(\beta)$ were tested for homogeneity. When regression coefficients were heterogeneous, cultivars were separated into uniform groups by visual inspection of the graphs. The regression coefficients of each group were retested for homogeneity. When the regression coefficients were homogeneous, the null hypothesis that $\beta_{\text {avg }}=0$ was tested.

The correlation between cultivar disease rating and the moles of PAR at specified photon flux densities accumulated during the inoculation period (Table 2) was examined using the PROC CORR procedure in SAS. Moles of PAR at a photon flux density of $\geq 475 \mu \mathrm{mol}$ $\mathrm{m}^{-2} \mathrm{~s}^{-1}$ had the greatest number of significant correlations with cultivar disease rating (Table 2). For this reason, moles of PAR at a photon flux density of $\geq 475 \mu \mathrm{mol} \mathrm{m} \mathrm{m}^{-2} \mathrm{~s}^{-1}$ was the environmental index used to test the influence of PAR on cultivar response to $S$. sclerotiorum. Photon flux density of PAR under cloudy conditions in the field $\left(\sim 200 \mu \mathrm{mol} \mathrm{m} \mathrm{m}^{-2} \mathrm{~s}^{-1}\right)$ is $\leq 10 \%$ full sunlight (10). The photon flux density of PAR used as the environmental index in our research was higher than commonly encountered in the field on cloudy days.

Temperature data were divided into three groups based on the temperature requirements for growth of S. sclerotiorum $\left(<19^{\circ} \mathrm{C}\right.$,

TABLE 3. Regression coefficient $(\beta)$, deviation from regression $\left(\Sigma \mathrm{d}^{2}{ }_{\mathrm{xy}}\right)$, and coefficient of determination $\left(r^{2}\right)$ for the regression of soybean cultivar disease rating ${ }^{\mathrm{a}}$ against the environmental index of mean disease rating of five experiments

\begin{tabular}{lrcc}
\hline & \multicolumn{3}{c}{ Disease rating } \\
\cline { 2 - 4 } Cultivar & $\beta$ & $\Sigma \mathrm{d}^{2}{ }_{\mathrm{xy}}$ & $r^{2}$ \\
\hline $\mathrm{A}$ & -0.28 & 0.007 & 0.53 \\
$\mathrm{~B}$ & 0.06 & 0.046 & 0.01 \\
$\mathrm{C}$ & 1.74 & 0.070 & 0.81 \\
$\mathrm{D}$ & 0.98 & 0.081 & 0.54 \\
$\mathrm{E}$ & 1.74 & 0.036 & 0.89 \\
$\mathrm{~F}$ & 1.01 & 0.030 & 0.77 \\
$\mathrm{G}$ & 1.24 & 0.022 & 0.87 \\
\hline
\end{tabular}

a The cultivars were inoculated with Sclerotinia sclerotiorum.

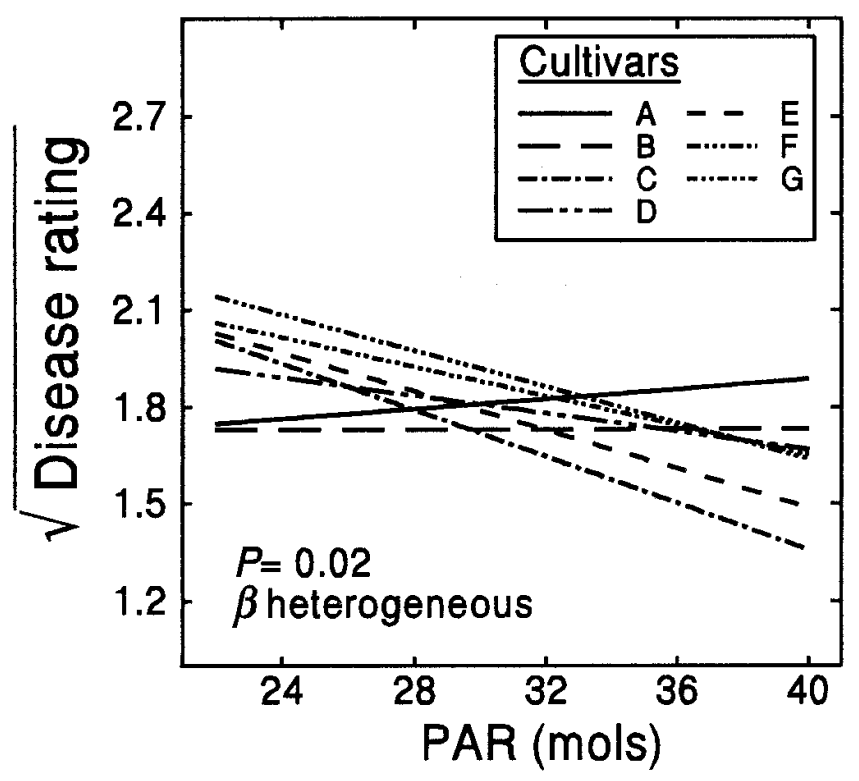

Fig. 2. Moles of photosynthetically active radiation (PAR) at a photon flux density of $\geq 475 \mu \mathrm{mol} \mathrm{m}^{-2} \mathrm{~s}^{-1}$ during the 48 -h inoculation period was the environmental index for stability analysis of soybean cultivar response to Sclerotinia sclerotiorum. Note that cultivar responses fall into two distinct groups. below optimum; 19 to $22^{\circ} \mathrm{C}$, optimum; and $>22^{\circ} \mathrm{C}$, above optimum) (26). The number of hours that the temperature was in the specified range during the 48-h inoculation period was used as the environmental index to test the influence of temperature on cultivar response.

\section{RESULTS AND DISCUSSION}

Plant breeders value cultivars that have stable responses across environments and frequently use stability analysis to examine genotype $\times$ environment interactions $(9,16)$. Accordingly, we used stability analysis to determine whether the physiological resistance to $S$. sclerotiorum detected in the greenhouse was sensitive to environmental conditions.

Stability analysis using the mean disease rating of each experiment as the environmental index detected a genotype $\times$ environment interaction in cultivar response to infection by S. sclerotiorum (Fig. 1). The regression coefficients were heterogeneous (Table 3); cultivars did not respond similarly over experiments. Further analysis found that the regression coefficients of cvs. A and B were homogeneous and not significantly different from zero. Their response to $S$. sclerotiorum was similar in all experiments. In contrast, the slopes of the remaining five cultivars were homogeneous and greater than $(P=0.001)$ zero; their response to $S$. sclerotiorum varied across experiments.

TABLE 4. Regression coefficient $(\beta)$, deviation from regression $\left(\Sigma \mathrm{d}^{2}{ }_{\mathrm{xy}}\right)$, and coefficient of determination $\left(r^{2}\right)$ for the regression of soybean cultivar disease rating ${ }^{\mathrm{a}}$ against the environmental index of moles of photosynthetically active radiation (PAR) at a photon flux density of $\geq 475 \mu \mathrm{mol} \mathrm{m}^{-2} \mathrm{~s}^{-1}$ during the 48 -h inoculation period of five experiments

\begin{tabular}{lccc}
\hline & \multicolumn{3}{c}{$\mathrm{PAR} \geq 475 \mu \mathrm{mol} \mathrm{m}^{-2} \mathrm{~s}^{-1}$} \\
\cline { 2 - 4 } Cultivar & $\beta$ & $\Sigma \mathrm{d}^{2} \mathrm{xy}$ & $r^{2}$ \\
\hline A & 0.008 & 0.002 & 0.87 \\
B & 0.0007 & 0.046 & 0.00 \\
C & -0.036 & 0.095 & 0.74 \\
D & -0.014 & 0.090 & 0.32 \\
E & -0.030 & 0.139 & 0.59 \\
F & -0.028 & 0.012 & 0.93 \\
G & -0.023 & 0.066 & 0.62 \\
\hline
\end{tabular}

${ }^{a}$ The cultivars were inoculated with Sclerotinia sclerotiorum.

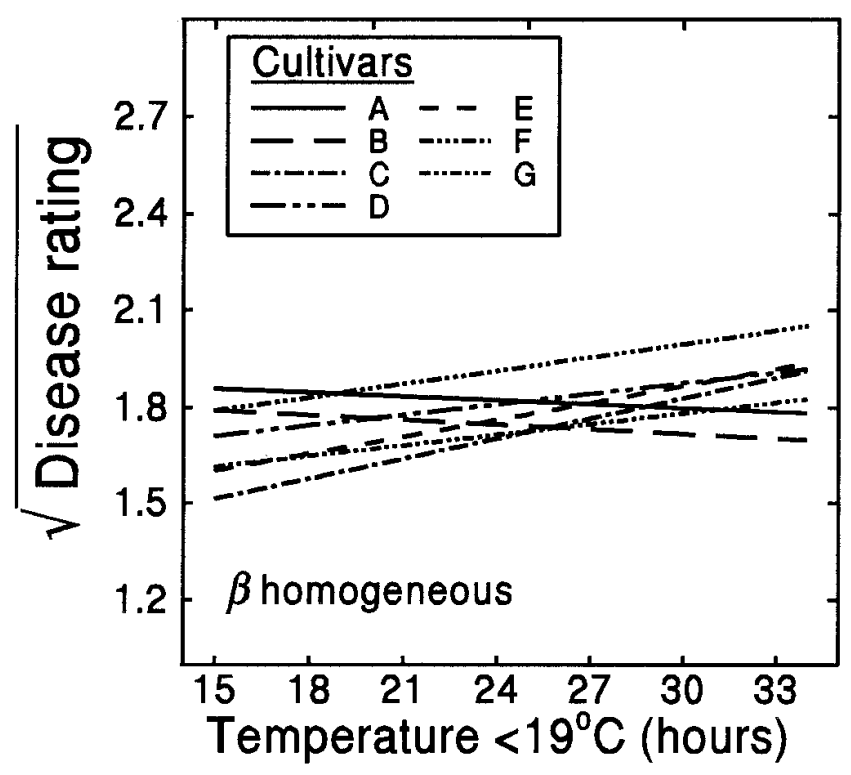

Fig. 3. Stability analysis of cultivar response to Sclerotinia sclerotiorum using hours that the temperature was $<19^{\circ} \mathrm{C}$ during the initial $48 \mathrm{~h}$ as the environmental index. All cultivars responded similarly, and there was a slight increase in disease rating as the time at low temperatures increased. 
Stability analysis relies on an environmental index that is not independent of the response variable when actual environmental data are not available (9). When the environmental index is not independent, regression coefficients $(\beta)$ that are $<1.0$ indicate stable genotypes and those that are $>1.0$ indicate genotypes that are sensitive to the environment (15). The environmental index was not independent in our analysis of mean experiment disease rating against individual cultivar disease ratings (Fig. 1). The $\beta$ values (Table 3 ) from our analysis clearly divided the seven cultivars into two groups. Cvs. A and B had a stable response to $S$. sclerotiorum, while the responses of the remaining cultivars were environmentally sensitive.

The availability of extensive PAR and temperature data allowed us to determine whether the genotype $\times$ environment interaction in soybean cultivars' response to $S$. sclerotiorum (Fig. 1) could be explained by environmental factors. When moles of PAR at a photon flux density of $\geq 475 \mu \mathrm{mol} \mathrm{m} \mathrm{m}^{-2} \mathrm{~s}^{-1}$ during the inoculation period was the environmental index (Fig. 2), cultivars' disease ratings fell into groupings identical to those that occurred when mean experiment disease rating was the environmental index (Fig. 1). The $\beta$ values (Table 4 ) for cvs. A and B were homogeneous and not significantly different from zero. In contrast, the negative $\beta$ values for the other five cultivars were homogeneous and less than $(P=0.001)$ zero. As the moles of PAR at a photon flux density of $\geq 475 \mu \mathrm{mol} \mathrm{m} \mathrm{m}^{-2} \mathrm{~s}^{-1}$ during the inoculation period increased, physiological resistance expressed by the five cultivars also increased. PAR appeared to explain the environmental sensitivity of the five cultivars identified as responsive to the environment (Fig. 1).

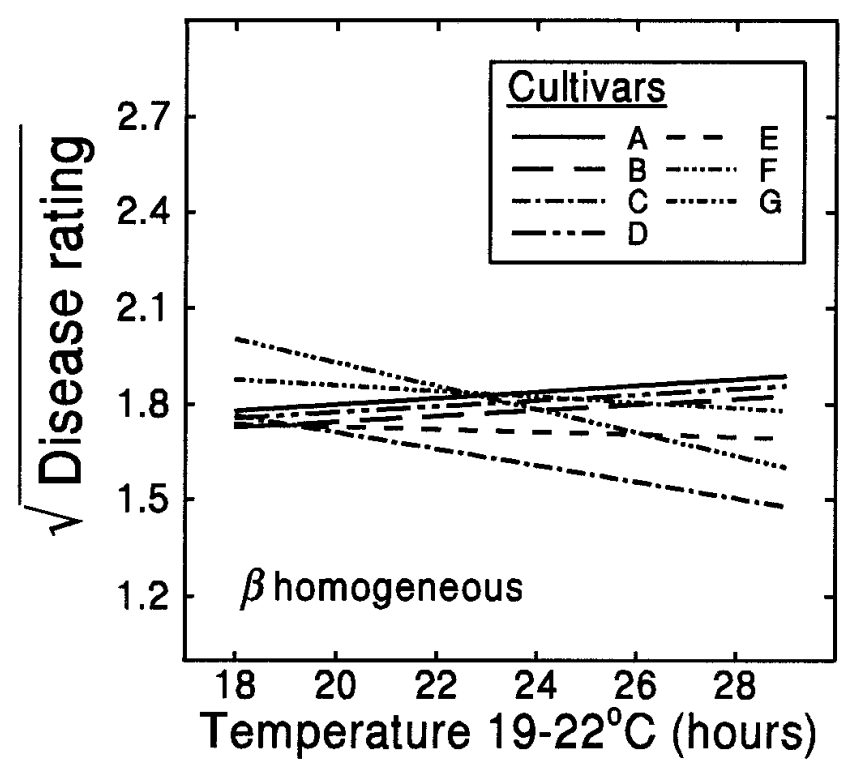

Fig. 4. Stability analysis of soybean cultivar response to Sclerotinia sclerotiorum using hours that the temperature was between 19 and $22^{\circ} \mathrm{C}$ during the 48-h inoculation period as the environmental index. All cultivars responded similarly, and the slopes were not significantly different from zero.
Physiological resistance was manifest in our experiments by a small, reddish-brown lesion at the inoculation point; susceptible plants were macerated. Physiological resistance involves a host response to infection that inhibits pathogen development and frequently involves products of the phenylpropanoid pathway $(8,21)$. The actual defense mechanisms may include (i) resistance to tissue breakdown, (ii) inherent antifungal materials, and (iii) the formation of phytoalexins (20). The production of the secondary metabolites used in defense reactions requires carbon skeletons and is sensitive to photosynthate production $(17,19)$. Low photon flux densities of PAR reduce photosynthesis, photosynthate production (10), and the expression of polygenic resistance (25). The PARsensitive response of five soybean cultivars and the PAR-insensitive response of the other two cultivars suggest the existence of different response mechanisms, one of which putatively relies on photosynthate-dependent defense compounds.

Although photon flux density of PAR appeared to explain the environmental sensitivity of cultivar response to $S$. sclerotiorum in our experiments, temperature also may have been involved. Stability analysis with hours that the temperature was $<19^{\circ} \mathrm{C}$ (Fig. 3), 19 to $22^{\circ} \mathrm{C}$ (Fig. 4), and $>22^{\circ} \mathrm{C}$ (Fig. 5) as environmental indices did not detect a genotype $\times$ environment interaction. The regression coefficients were homogeneous in all three cases (Table 5). They were not significantly different from zero for hours that the temperature was 19 to $22^{\circ} \mathrm{C}$ (Fig. 4) and $>22^{\circ} \mathrm{C}$ (Fig. 5). In contrast, there was a slight $(P=0.10)$ positive slope in cultivar response to temperatures of $<19^{\circ} \mathrm{C}$. The disease rating of all cultivars

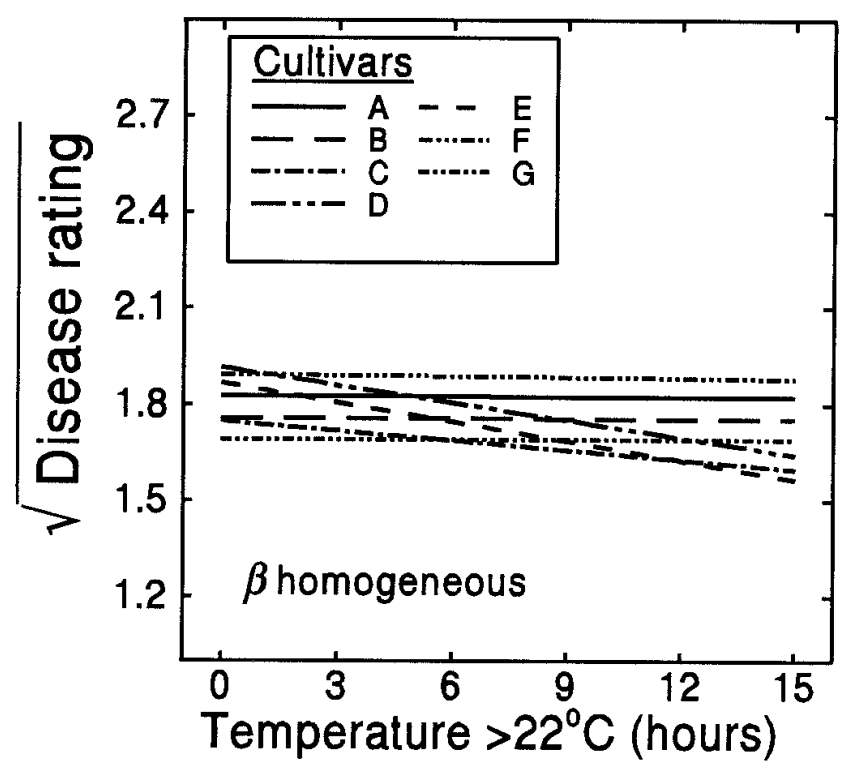

Fig. 5. Stability analysis of soybean cultivar response to Sclerotinia sclerotiorum using hours that the temperature was above $22^{\circ} \mathrm{C}$ during the 48 -h inoculation period as the environmental index. All cultivars responded similarly, and the slopes were not significantly different from zero.

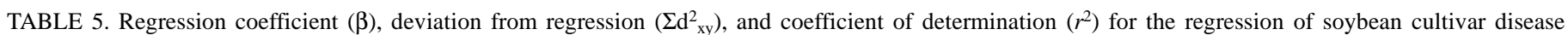

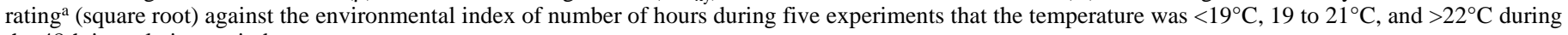
the 48-h inoculation period

\begin{tabular}{|c|c|c|c|c|c|c|c|c|c|}
\hline \multirow[b]{2}{*}{ Cultivar } & \multicolumn{3}{|c|}{$<19^{\circ} \mathrm{C}$} & \multicolumn{3}{|c|}{19 to $22^{\circ} \mathrm{C}$} & \multicolumn{3}{|c|}{$>22^{\circ} \mathrm{C}$} \\
\hline & $\beta$ & $\Sigma \mathrm{d}_{\mathrm{xy}}^{2}$ & $r^{2}$ & $\beta$ & $\Sigma \mathrm{d}^{2}{ }_{\mathrm{xy}}$ & $r^{2}$ & $\beta$ & $\Sigma \mathrm{d}_{\mathrm{xy}}^{2}$ & $r^{2}$ \\
\hline $\mathrm{A}$ & -0.004 & 0.011 & 0.28 & 0.010 & 0.006 & 0.61 & -0.00003 & 0.015 & 0.00 \\
\hline B & -0.005 & 0.041 & 0.11 & 0.009 & 0.039 & 0.14 & -0.0003 & 0.046 & 0.00 \\
\hline $\mathrm{C}$ & 0.021 & 0.276 & 0.26 & -0.026 & 0.318 & 0.14 & -0.010 & 0.359 & 0.03 \\
\hline $\mathrm{D}$ & 0.011 & 0.106 & 0.20 & 0.009 & 0.125 & 0.05 & -0.018 & 0.089 & 0.32 \\
\hline $\mathrm{E}$ & 0.018 & 0.270 & 0.19 & -0.004 & 0.338 & 0.00 & -0.0207 & 0.285 & 0.16 \\
\hline $\mathrm{F}$ & 0.014 & 0.137 & 0.22 & -0.037 & 0.069 & 0.61 & -0.0009 & 0.177 & 0.00 \\
\hline $\mathrm{G}$ & 0.017 & 0.114 & 0.35 & -0.009 & 0.168 & 0.04 & -0.014 & 0.149 & 0.14 \\
\hline
\end{tabular}

a The cultivars were inoculated with Sclerotinia sclerotiorum. 
increased as the time at low temperatures increased. $S$. sclerotiorum grows at temperatures as low as $15^{\circ} \mathrm{C}(26)$, whereas soybean photosynthetic rate diminishes below $20^{\circ} \mathrm{C}$ (27). The slight increase in disease rating in response to increased time at $<19^{\circ} \mathrm{C}$ suggests the hypothesis that low temperature may inhibit the soybean's ability to produce the photosynthate needed for defense compounds.

The lack of correlation between greenhouse and field tests impedes development of soybean cultivars that are resistant to $S$. sclerotiorum. Grau and Bissonnett (14) observed that the cv. Clay is susceptible in the greenhouse but resistant in field tests. Boland and Hall (4) found no correlation between greenhouse and field evaluations for Sclerotinia stem rot resistance, and Chun et al. (6) found significance in only $12 \%$ of the correlations between laboratory and field results. Nelson et al. (23) speculated that light differences might contribute to the lack of correlation between greenhouse and field screening results. Our results support the hypothesis that photon flux density of PAR influences the expression of physiological resistance to $S$. sclerotiorum. The sensitivity of soybean cultivar response to PAR may partially explain the lack of correlation noted between greenhouse and field screening for Sclerotinia stem rot resistance. The PAR-sensitive and PAR-insensitive cultivar responses to $S$. sclerotiorum also may be a factor in the genotype $\times$ environment interactions that complicate breeding for resistance to $S$. sclerotiorum in soybean. The disease rating of cultivars with the PAR-sensitive response to $S$. sclerotiorum would vary across environments; those with a PAR-insensitive response might be more stable.

\section{ACKNOWLEDGMENTS}

The research was supported by grants from The Pennsylvania Soybean Promotion Board. We thank L. Rhodes, Department of Plant Pathology, Ohio State University, for the isolate of Sclerotinia sclerotiorum; W. Stout, USDAARS, Pasture Systems and Watershed Management Group, University Park, PA, for the Campbell datalogger and thermistors; D. Knievel, Department of Agronomy, Penn State, for the LICOR quantum sensors; and R. Dickerson, Department of Agronomy, Penn State, for technical assistance.

\section{LITERATURE CITED}

1. Abawi, G. S., and Grogan, R. G. 1979. Epidemiology of diseases caused by Sclerotinia species. Phytopathology 69:899-904.

2. Anonymous. 1995. White mold takes toll in northern corn belt. Success. Farming 93:50.

3. Boland, G. J., and Hall, R. 1986. Growth room evaluation of soybean cultivars for resistance to Sclerotinia sclerotiorum. Can. J. Plant Sci. 66: 559-564.

4. Boland, G. J., and Hall, R. 1987. Evaluating soybean cultivars for resistance to Sclerotinia sclerotiorum under field conditions. Plant Dis. 71: 934-936.

5. Boland, G. J., and Hall, R. 1988. Epidemiology of Sclerotinia stem rot of soybean in Ontario. Phytopathology 78:1241-1245.

6. Chun, D., Kao, L. B., Lockwood, J. L., and Isleib, T. G. 1987. Laboratory and field assessment of resistance in soybean to stem rot caused by Sclerotinia sclerotiorum. Plant Dis. 71:811-815.

7. Cline, M. N., and Jacobsen, B. J. 1983. Methods for evaluating soybean cultivars for resistance to Sclerotinia sclerotiorum. Plant Dis. 67:784-786.
8. Dixon, R. A., and Paiva, M. L. 1995. Stress-induced phenylpropanoid metabolism. Plant Cell 7:1085-1097.

9. Eberhart, S. A., and Russell, W. A. 1966. Stability parameters for comparing varieties. Crop Sci. 6:36-40.

10. Fritter, A. H., and Hay, R. K. M. 1987. Energy and carbon. Pages 24-65 in: Environmental Physiology of Plants. Academic Press, New York.

11. Fuller, P. A., Coyne, D. P., and Steadman, J. R. 1984. Inheritance of resistance to white mold disease in a diallel cross of dry beans. Crop Sci. 24:929-933.

12. Gomez, K. A., and Gomez, A. A. 1984. Regression and correlation analysis. Pages 357-423 in: Statistical Procedures for Agricultural Research. John Wiley \& Sons, New York.

13. Grau, C. R. 1988. Sclerotinia stem rot of soybean. Pages 56-66 in: Soybean Diseases of the North Central Region. T. D. Wyllie and D. H. Scott, eds. The American Phytopathological Society, St. Paul, MN.

14. Grau, C. R., and Bissonnett, H. L. 1974. Whetzelinia stem rot of soybean in Minnesota. Plant Dis. Rep. 58:693-695.

15. Grau, C. R., and Radke, V. L. 1984. Effects of cultivars and cultural practices on Sclerotinia stem rot of soybean. Plant Dis. 68:56-58

16. Heinrich, G. M., Francis, C. A., and Eastin, J. D. 1983. Stability of grain sorghum yield components across diverse environments. Crop Sci. 23: 209-212.

17. Herrmann, K. M. 1995. The shikimate pathway: Early steps in the biosynthesis of aromatic compounds. Plant Cell 7:907-919.

18. Hunter, J. E., Dickson, M. H., and Cigna, J. A. 1981. Limited-term inoculation: A method to screen bean plants for partial resistance to white mold. Plant Dis. 65:414-417.

19. Ireland, R. 1990. Amino acid and ureide biosynthesis. Pages 407-421 in: Plant Physiology, Biochemistry and Molecular Biology. D. T. Dennis and D. H. Turpin, eds. Longman Scientific and Technical, Essex, England.

20. Lumsden, R. D. 1979. Histology and physiology of pathogenesis in plant diseases caused by Sclerotinia species. Phytopathology 69:890-896.

21. Miklas, P. N., Grafton, K. F., and McClean, P. E. 1993. Estimating phenylalanine ammonia-lyase activity in common beans inoculated with Sclerotinia sclerotiorum. HortScience 28:937-938.

22. Mueller, D. S., Hoffman, D. D., Nickell, C. D., Hartman, G. L., and Pedersen, W. L. 1997. Potential seed transmission of white mold on soybeans. (Abstr.) Phytopathology 87(suppl.):S68.

23. Nelson, B. D., Helms, T. C., and Olson, M. A. 1991. Comparisons of laboratory and field evaluations of resistance in soybean to Sclerotinia sclerotiorum. Plant Dis. 75:662-665.

24. Pennypacker, B. W., and Hatley, O. E. 1995. Greenhouse technique for detection of physiological resistance to Sclerotinia sclerotiorum in soybean. (Abstr.) Phytopathology 85:1178.

25. Pennypacker, B. W., Knievel, D. P., Risius, M. L., and Leath, K. T. 1994. Photosynthetic photon flux density $\times$ pathogen interaction in growth of alfalfa infected with Verticillium albo-atrum. Phytopathology 84:1350-1358.

26. Phipps, P. M., and Porter, D. M. 1982. Sclerotinia blight of soybean caused by Sclerotinia minor and Sclerotinia sclerotiorum. Plant Dis. 66: 163-165.

27. Shibles, R., Secor, J., and Ford, D. M. 1987. Carbon assimilation and metabolism. Pages 535-588 in: Soybeans: Improvement, Production, and Uses. Agronomy Monograph 16. J. R. Wilcox, ed. ASA-CSSA-SSSA, Madison, WI.

28. Smith, K. J., and Huyser, W. 1987. World distribution and significance of soybean. Pages 1-22 in: Soybeans: Improvement, Production, and Uses. Agronomy Monograph 16. J. R. Wilcox, ed. ASA-CSSA-SSSA, Madison, WI.

29. Steadman, J. R. 1979. Control of plant diseases caused by Sclerotinia species. Phytopathology 69:904-907.

30. Yang, X. B., Wegulo, S., Lundeen, P., Martinson, C., and Workneh, F. 1997. Assessment of dissemination of Sclerotinia sclerotiorum, causal agent of soybean sclerotinia stem rot. (Abstr.) Phytopathology 87(suppl.):S106. 